\title{
A Cysteine-Rich CCG Domain Contains a Novel [4Fe-4S] Cluster Binding Motif As Deduced from Studies with Subunit B of Heterodisulfide Reductase from Methanothermobacter marburgensis ${ }^{\dagger}$
}

\author{
Nils Hamann $\S$, Gerd J. Mander $§$, Jacob E. Shokes ${ }^{\ddagger}$, Robert A. Scott ${ }^{\ddagger}$, Marina Bennati ${ }^{\perp}$, and \\ Reiner Hedderich ${ }^{*}, \S$ \\ Max Planck Institute for Terrestrial Microbiology, Karl-von-Frisch Strasse, D-35043 Marburg, \\ Germany, Department of Chemistry and Center for Metalloenzyme Studies, University of \\ Georgia, Athens, Georgia 30602-2556, and Institute of Physical and Theoretical Chemistry and \\ Center for Biomolecular Magnetic Resonance, J. Goethe University of Frankfurt, D-60438 \\ Frankfurt, Germany
}

\section{Abstract}

Heterodisulfide reductase (HDR) of methanogenic archaea with its active-site [4Fe-4S] cluster catalyzes the reversible reduction of the heterodisulfide (CoM-S-S-CoB) of the methanogenic coenzyme M (CoM-SH) and coenzyme B (CoB-SH). CoM-HDR, a mechanistic-based paramagnetic intermediate generated upon half-reaction of the oxidized enzyme with $\mathrm{CoM}-\mathrm{SH}$, is a novel type of $[4 \mathrm{Fe}-4 \mathrm{~S}]^{3+}$ cluster with $\mathrm{CoM}-\mathrm{SH}$ as a ligand. Subunit $\mathrm{HdrB}$ of the Methanothermobacter marburgensis $\mathrm{HdrABC}$ holoenzyme contains two cysteine-rich sequence motifs ( $\left.\mathrm{CX}_{31-39} \mathrm{CCX}_{35-36} \mathrm{CXXC}\right)$, designated as $\mathrm{CCG}$ domain in the Pfam database and conserved in many proteins. Here we present experimental evidence that the $\mathrm{C}$-terminal CCG domain of $\mathrm{HdrB}$ binds this unusual [4Fe-4S] cluster. $\mathrm{HdrB}$ was produced in Escherichia coli, and an iron-sulfur cluster was subsequently inserted by in vitro reconstitution. In the oxidized state the cluster without the substrate exhibited a rhombic EPR signal $\left(g_{z y x}=2.015,1.995\right.$, and 1.950) reminiscent of the CoM-HDR signal. ${ }^{57} \mathrm{Fe}$ ENDOR spectroscopy revealed that this paramagnetic species is a [4Fe-4S] cluster with ${ }^{57} \mathrm{Fe}$ hyperfine couplings very similar to that of CoM-HDR. $\mathrm{CoM}^{-33} \mathrm{SH}$ resulted in a broadening of the EPR signal, and upon addition of CoM-SH the midpoint potential of the cluster was shifted to values observed for CoM-HDR, both indicating binding of CoM-SH to the cluster. Site-directed mutagenesis of all 12 cysteine residues in HdrB identified four cysteines of the C-terminal CCG domain as cluster ligands. Combined with the previous detection of CoM-HDR-like EPR signals in other CCG domain-containing proteins our data indicate a general role of the $\mathrm{C}$-terminal CCG domain in coordination of this novel [4Fe-4S] cluster. In addition, Zn K-edge X-ray absorption spectroscopy identified an isolated Zn site with

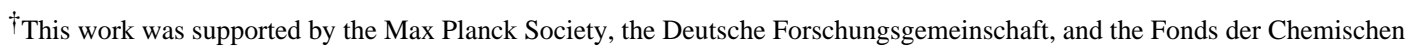
Industrie.

(C) 2007 American Chemical Society

*To whom correspondence should be addressed. Phone: +49-(0)-6421-178-230. Fax: +49-(0)6421-178-299. hedderic@ mpimarburg.mpg.de.

\$ax Planck Institute for Terrestrial Microbiology.

†University of Georgia.

$\perp_{\text {University of Frankfurt. }}$
}

SUPPORTING INFORMATION AVAILABLE

Sequences of oligonucleotides used in polymerase chain reactions (Table S1) and primer combinations and restriction sites used for mutations in $h d r B$ from Methanothermobacter marburgensis (Table S2). This material is available free of charge via the Internet at http://pubs.acs.org. 
an $\mathrm{S}_{3}(\mathrm{O} / \mathrm{N})_{1}$ geometry in $\mathrm{HdrB}$ and the HDR holoenzyme. The $\mathrm{N}$-terminal CCG domain is suggested to provide ligands to the $\mathrm{Zn}$ site.

Heterodisulfide reductase (HDR ${ }^{1}$ ) (EC 1.8.98.1) is a unique disulfide reductase with a key function in the energy metabolism of methane-producing archaea. The enzyme catalyzes the reversible reduction of the mixed disulfide (CoM-S-S-CoB) of the two methanogenic thiol coenzymes, designated coenzyme $\mathrm{M}(\mathrm{CoM}-\mathrm{SH})$ and coenzyme $\mathrm{B}(\mathrm{CoB}-\mathrm{SH})$. This disulfide is generated in the final step of methanogenesis $(1,2)$.

Two types of HDRs from phylogenetically distantly related methanogens, represented by the enzymes from Methanothermobacter marburgensis (3) and from Methanosarcina barkeri and Methanosarcina thermophila $(4,5)$, have been identified and characterized $(1,6)$. Neither type of enzyme belongs to the family of pyridine nucleotide disulfide oxidoreductases (7). HDR from $M$. marburgensis is an iron-sulfur flavoprotein composed of three subunits: $\mathrm{HdrA}, \mathrm{HdrB}$, and $\mathrm{HdrC}$. The primary sequence of HdrA indicates that it contains the FAD binding site and four canonical binding motifs for [4Fe-4S] clusters. HdrB contains no sequence motif characteristic for the binding of known cofactors but has two unique cysteine-rich sequence motifs $\left(\mathrm{CX}_{31-39} \mathrm{CCX}_{35-36} \mathrm{CXXC}\right)$ of unknown function, designated as the CCG domain in the Pfam protein families database (accession number PF02754) (8). The ferredoxin-like subunit $\mathrm{HdrC}$ contains two canonical binding motifs for [4Fe-4S] clusters (9). HDR from Methanosarcina species lacks a homologue of the M. marburgensis $\mathrm{HdrA}$ subunit, whereas subunits $\mathrm{HdrC}$ and $\mathrm{HdrB}$ are conserved in the putative fusion protein HdrD (Figure 1). Subunits HdrC and HdrB are also conserved in subunit TfrB of thiol:fumarate reductase (TFR) (Figure 1), an anabolic enzyme of methanogens that catalyzes the reduction of fumarate to succinate with CoM-SH plus CoB-SH as electron donors (10). HDR with highly conserved $\mathrm{HdrB}$ and $\mathrm{HdrC}$ subunits is also encoded by the genomes of uncultivated anaerobic methanotrophic archaea in which the enzyme is thought to catalyze formation of CoM-S-S-CoB from CoM-SH and CoB-SH during anaerobic methane oxidation (11).

Studies focused on elucidation of the catalytic mechanism of HDR performed with both the enzyme from M. marburgensis and M. barkeri led to identification of a mechanistic-based paramagnetic intermediate generated upon half-reaction of the oxidized enzyme with CoMSH in the absence of CoB-SH $(12,14)$. The $S=1 / 2$ species, designated as CoM-HDR, is observed at temperatures below $50 \mathrm{~K}$ with principal $g$ values of 2.013, 1.991, and 1.938 ( $M$. marburgensis $\mathrm{HDR})$. The resonance is lost on reduction $\left(E_{\mathrm{m}}=-185 \mathrm{mV}\right.$ versus $\mathrm{NHE}$ at $\mathrm{pH}$ 7.6) and on reaction with $\mathrm{CoB}-\mathrm{SH}$. Hence, it was attributed to the product of the oxidative half-reaction that occurs in the absence of $\mathrm{CoB}-\mathrm{SH}$ in which case it is likely to correspond to a trapped intermediate in the catalytic cycle. Signal broadening in the ${ }^{57} \mathrm{Fe}$-enriched enzyme indicated that the intermediate is iron based. The combination of variable-temperature magnetic circular dichroism (VT-MCD) spectroscopy and EPR spectroscopy with ${ }^{33} \mathrm{~S}$ labeled CoM-SH led to the proposal that the CoM-HDR reaction intermediate is a novel substrate-bound $[4 \mathrm{Fe}-4 \mathrm{~S}]^{3+}$ cluster with two thiolate ligands at a unique $\mathrm{Fe}$ site $(13$, 14). ${ }^{57} \mathrm{Fe}$-pulsed ENDOR at two very different frequencies, 9 and $94 \mathrm{GHz}$, provided direct evidence for a $[4 \mathrm{Fe}-4 \mathrm{~S}]$ cluster with unusually large ${ }^{57} \mathrm{Fe}$ isotropic hyperfine coupling values, which reveals the unusual nature of the cluster (15). From these data it was concluded that HDR uses an active-site iron-sulfur cluster to mediate disulfide reduction in two one-electron steps via site-specific cluster chemistry $(6,13)$. The sequence of HDR is

\footnotetext{
${ }^{1}$ Abbreviations: HDR, heterodisulfide reductase; TFR, thiol:fumarate reductase; PCR, polymerase chain reaction; EPR, electron paramagnetic resonance; XAS, X-ray absorption spectroscopy; ENDOR, electron-nuclear double resonance; DTT, dithiothreitol; $\mathrm{CoM}-\mathrm{SH}$, coenzyme M or 2-mercaptoethane sulfonate; CoB-SH, coenzyme B or 7-mercapto-heptanoylthreonine phosphate; CoM-S$\mathrm{S}-\mathrm{CoB}$, heterodisulfide of $\mathrm{CoM}-\mathrm{SH}$ and $\mathrm{CoB}-\mathrm{SH}$.
} 
not related to that of ferredoxin: thioredoxin reductase (FTR), the only other known enzyme which uses an active-site $[4 \mathrm{Fe}-4 \mathrm{~S}]$ cluster to mediate disulfide reduction $(16,17)$.

An assignment of the active-site cluster to a specific subunit has not yet been achieved. It has been suggested that cysteine residues present in the two CCG domains of $M$. marburgensis $\mathrm{HdrB}, M$. barkeri $\mathrm{HdrD}$ and $M$. marburgensis $\mathrm{TfrB}$ (Figure 1), could provide the ligands to this cluster $(4,10)$. A database search indicates that the CCG domain is also conserved in a large number of proteins from non-methanogens in the archaeal and bacterial domain. This protein family currently has 1871 members. In most of these proteins the CCG domain is present in two copies, but in some proteins the N-terminal CCG domain is degenerated and conserved cysteine residues are replaced by other amino acid residues. The role of a CCG domain has not been defined for any of these proteins (6).

In previous studies $\mathrm{HdrB}$ was produced in Bacillus subtilis to address the function of its CCG domains (12). M. marburgensis HdrB rather than M. barkeri HdrD was selected because it contains no additional canonical iron-sulfur cluster binding motifs (Figure 1). Heterologous production of $\mathrm{HdrB}$ resulted in a protein containing a [2Fe-2S] cluster as deduced by UV/vis absorption, MCD, and resonance Raman spectroscopies. The cluster was labile and irreversibly lost upon reduction. Since a [2Fe-2S] cluster was not observed in native $\mathrm{HdrABC}$ it was considered as an artifact of the heterologous expression system (12). Here we reinvestigated the heterologous production of $\mathrm{HdrB}$ using $E$. coli as the expression host. We present evidence that after an in vitro reconstitution step a [4Fe-4S] cluster with spectroscopic properties reminiscent of CoM-HDR was generated. The cluster ligands are located in the C-terminal CCG domain as shown by site-directed mutagenesis. Via X-ray absorption spectroscopy a $\mathrm{Zn}$ site was identified in $\mathrm{HdrB}$, proposed to be coordinated by cysteine residues of the $\mathrm{N}$-terminal CCG domain. This work provides the first assignment of a CCG domain as an iron-sulfur cluster binding site and establishes the basis for future studies on the widespread CCG domain proteins.

\section{EXPERIMENTAL PROCEDURES}

\section{Materials}

Coenzyme M was from Merck (Darmstadt). Coenzyme B and CoM-S-S-CoB were synthesized as described previously (18). CoM- ${ }^{33} \mathrm{SH}$ was synthesized as described in ref 14 . All other chemicals were from Merck (Darmstadt) or Sigma (Taufkirchen).

\section{Heterologous Production of HdrB in E. coli}

The $h d r B$ gene from M. marburgensis (GeneBank Accession Number X81133) was amplified by PCR using genomic DNA as template and the oligonucleotides $5^{\prime}$ CATATGGAAATCG-CATACTTTTTAGG-3' and 5' -GCGGCCGCTTAACCGCTTCCAGGTGCC- $3^{\prime}$ as primers. After gel extraction, the obtained PCR product was cloned in pCR2.1-TOPO (Invitrogen, Karlsruhe). The NdeI and Notl restriction sites thus generated were used to subclone the $h d r B$ gene into pET-24b(+) (Novagen, Darmstadt) generating pET-24- $h d r B$. The sequence of the $h d r B$ insert was confirmed by DNA sequencing. For expression of $h d r B, E$. coli BL21(DE3)-pCodonPlus-RIL (Stratagene) was first transformed with pRKISC containing the $E$. coli isc locus (19). This plasmid has been successfully used for production of iron-sulfur proteins (20). The resulting strain was transformed with pET-24- $h d r B$. For heterologous production of $\mathrm{HdrB}, E$. coli transformants were grown in 1 $\mathrm{L}$ of medium at $37^{\circ} \mathrm{C}$ on a magnetic stirrer $(1000 \mathrm{rpm})$. The optimized expression medium contained (per liter) $15 \mathrm{~g}$ of yeast extract, $20 \mathrm{~g}$ of Bacto casamino acids, $2 \mathrm{~g}$ of $\mathrm{Na}_{2} \mathrm{HPO}_{4} \cdot 2 \mathrm{H}_{2} \mathrm{O}, 1 \mathrm{~g}$ of $\mathrm{KH}_{2}-\mathrm{PO}_{4}$, and $8 \mathrm{~g}$ of $\mathrm{NaCl}$. After autoclaving, filter-sterilized components were added: kanamycin $(100 \mathrm{mg} / \mathrm{L})$, chloramphenicol $(50 \mathrm{mg} / \mathrm{L})$, tetracycline 
(15 mg/L), glucose $(2.5 \mathrm{~g} / \mathrm{L})$, cysteine $\cdot \mathrm{HCl}(177 \mathrm{mg} / \mathrm{L})$, and $\mathrm{FeCl}_{2} \cdot 4 \mathrm{H}_{2} \mathrm{O}(10 \mathrm{mg} / \mathrm{L})$. At a $\triangle \mathrm{OD}_{600}$ of $1.2, h d r B$ expression was induced by addition of $1 \mathrm{mM}$ IPTG. The culture was subsequently incubated for $24 \mathrm{~h}$ at $25^{\circ} \mathrm{C}$ with aeration followed by an additional $24 \mathrm{~h}$ incubation without agitation. Cells were harvested by centrifugation and stored at $-80{ }^{\circ} \mathrm{C}$.

All subsequent steps were performed under anoxic conditions. Cells ( $4 \mathrm{~g}$ wet mass) were suspended in $20 \mathrm{~mL}$ of $50 \mathrm{mM}$ Tris/ $\mathrm{HCl} \mathrm{pH} 7.6$ containing $2 \mathrm{mM}$ dithiothreitol (DTT). The suspension was passed three times through a FrenchPress standard cell at $110 \mathrm{MPa}$. For in vitro reconstitution of the iron-sulfur cluster (21) the following components were added to the crude lysate (final concentration): Tris/ $\mathrm{HCl} \mathrm{pH} 8.1$ (75 mM), $\mathrm{FeCl}_{2}(0.54 \mathrm{mM})$, cysteine $(2 \mathrm{mM})$, DTT $(7 \mathrm{mM})$, and $\mathrm{Na}_{2} \mathrm{~S}(2 \mathrm{mM})$. The mixture $(100 \mathrm{~mL})$ was incubated with agitation for $12 \mathrm{~h}$ at $25^{\circ} \mathrm{C}$.

Insoluble components were removed by centrifugation at $52000 \mathrm{~g}$ for $1 \mathrm{~h}$. The supernatant was diluted 1:3 with $50 \mathrm{mM}$ Tris/ $\mathrm{HCl} \mathrm{pH} 7.6+2 \mathrm{mM}$ DTT and applied to a Q-Sepharose high-performance column $(2.6 \mathrm{~cm} \times 10 \mathrm{~cm}$; GE Healthcare, Muenchen) equilibrated with the same buffer. Protein was eluted with $\mathrm{NaCl}$ using a step gradient. HdrB eluted at $0.48 \mathrm{M}$ $\mathrm{NaCl}$. The protein was detected via Western-blot analysis using a fluorescent Western blotting system (ECF, GE Healthcare) according to the protocol provided by the supplier and 1:3000 dilutions of rabbit anti-(HdrABC) sera and 1:10 000 dilutions of alkaline phosphatase-conjugated anti-(rabbit IgG) antibodies (Bio-Rad, Muenchen). The sample was then adjusted to an ammonium sulfate concentration of $1 \mathrm{M}$ and subjected to a second chromatographic step using a Phenyl-Sepharose column $(2.6 \mathrm{~cm} \times 10 \mathrm{~cm}$; GE Healthcare, Muenchen). HdrB eluted at $0 \mathrm{M}$ ammonium sulfate. HdrB was concentrated and desalted by ultrafiltration (Amicon Ultra-4, 10-kDa cutoff; Millipore, Eschborn). The purified protein was $>98 \%$ pure as judged by SDS-PAGE, and its identity was confirmed using Western blot analysis and peptide mass fingerprinting. For peptide mass fingerprint the protein was digested with trypsin, and the peptide masses were determined using a Voyager DE RP MALDI time-of-flight mass spectrometer (Applied Biosystems, Darmstadt). The sequence coverage was $25 \%$. For enrichment of $\mathrm{HdrB}$ with ${ }^{57} \mathrm{Fe},{ }^{57} \mathrm{FeCl}_{3}$ was added to the E. coli medium and the in vitro reconstitution mixture at the concentrations indicated above. ${ }^{57} \mathrm{FeCl}_{3}$ was prepared by dissolving metallic ${ }^{57} \mathrm{Fe}(96 \%$ enriched) (Chemotrade, Duesseldorf) in $36 \%(\mathrm{w} / \mathrm{v}) \mathrm{HCl}$ at $80{ }^{\circ} \mathrm{C}$ for $12 \mathrm{~h}$.

\section{Site-Directed Mutagenesis}

Point mutations were generated by oligonucleotide-directed mutagenesis (22) using pET-24$h d r B$ as the PCR template. For each mutation two or three primers were designed. PCR products containing the desired mutations were cloned into pET-24- $h d r B$ using existing restriction sites. The $h d r B$ inserts were sequenced to verify that the selected clones only contained the desired mutations. The sequences of oligonucleotides used to generate the different Cys to Ser mutants are provided as Supporting Information (Table S1). Primer combinations and restriction sites used are shown in Table S2.

\section{EPR Spectroscopy}

X-band $(9 \mathrm{GHz})$ EPR spectra were obtained with a Bruker EMX spectrometer. All spectra were recorded with a field modulation frequency of $100 \mathrm{kHz}$. Samples were cooled with an Oxford Instruments ESR 900 flow cryostat and an ITC4 temperature controller. Spin quantitations were carried out under nonsaturating conditions using $10 \mathrm{mM}$ copper perchlorate as the standard $\left(10 \mathrm{mM} \mathrm{CuSO}_{4}, 2 \mathrm{mM} \mathrm{NaClO}_{4}, 10 \mathrm{mM} \mathrm{HCl}\right)$. When the EPR signals overlapped with other signals, e.g., radical signals from the redox dyes, the signals were simulated and the simulations were double integrated to obtain the spin intensity. Temperature dependencies were determined under nonsaturating conditions. For all signals 
the peak amplitude was measured at different temperatures. These values were used to obtain Curie plots describing the temperature behavior of the respective EPR signals. EPR spectra were simulated using our own programs based on formulas described earlier (23).

\section{EPR-Monitored Redox Titrations}

Redox titrations were performed at $20{ }^{\circ} \mathrm{C}$ under an $\mathrm{N}_{2} / \mathrm{H}_{2}(95 / 5$, v/v) atmosphere. Potentials were adjusted with small amounts of freshly prepared sodium dithionite $(10$ or $100 \mathrm{mM}$ stock solutions) or freshly prepared potassium ferricyanide (15 or $150 \mathrm{mM}$ stock solutions). All redox potentials quoted here are expressed relative to the normal hydrogen electrode. In these titrations a selection of the following mediators (final concentration $20 \mu \mathrm{M}$ ) were added to the enzyme solution, depending on the potential range investigated: 1,4-benzoquinone $\left(E^{\mathrm{o}^{\prime}}=+274 \mathrm{mV}\right), 1,2$-naphthoquinone-4-sulfonate $\left(E^{\mathrm{o}^{\prime}}=+215 \mathrm{mV}\right), 1,2$ naphthoquinone $\left(E^{\circ}=+134 \mathrm{mV}\right)$, duroquinone $\left(E^{\prime \prime}=+86 \mathrm{mV}\right), 1,4$-naphthoquinone $\left(E^{\circ}\right.$ $=+69 \mathrm{mV})$, thionine $\left(E^{0^{\prime}}=+64 \mathrm{mV}\right)$, methylene blue $\left(E^{0^{\prime}}=+11 \mathrm{mV}\right)$, indigo disulfonate $\left(E^{0^{\prime}}=-125 \mathrm{mV}\right)$, 2-hydroxy-1,4-naphthoquinone $\left(E^{0^{\prime}}=-145 \mathrm{mV}\right)$, anthraquinone-1,5disulfonate $\left(E^{\circ}=-170 \mathrm{mV}\right)$, phenosafranin $\left(E^{\circ}=-252 \mathrm{mV}\right)$, anthraquinone-2-sulfonate $\left(E^{\mathrm{o}^{\prime}}=-255 \mathrm{mV}\right)$, safranin $\mathrm{O}\left(E^{\mathrm{O}^{\prime}}=-289 \mathrm{mV}\right)$, neutral red $\left(E^{\mathrm{O}^{\prime}}=-325 \mathrm{mV}\right)$, benzyl viologen $\left(E^{0^{\prime}}=-350 \mathrm{mV}\right)$, and methyl viologen $\left(E^{0^{\prime}}=-453 \mathrm{mV}\right)$. HdrB was added to a final concentration of $60 \mu \mathrm{M}$ in $50 \mathrm{mM}$ Tris/ $\mathrm{HCl} \mathrm{pH} \mathrm{7.6.} \mathrm{After} \mathrm{stabilization} \mathrm{of} \mathrm{the} \mathrm{desired}$ redox potential, a $0.3 \mathrm{~mL}$ aliquot was transferred to a calibrated EPR tube and immediately frozen in liquid nitrogen. The redox potential was measured with a $\mathrm{Ag} / \mathrm{AgCl}$ redox combination electrode (Mettler Toledo, Giessen). To obtain midpoint potentials relative to the normal hydrogen electrode, a value of $207 \mathrm{mV}$ (corresponding to the potential of $\mathrm{Ag} /$ $\mathrm{AgCl}$ at $25^{\circ} \mathrm{C}$ ) was added to the measured redox potentials. Calculations of the Nernst curves $(n=1)$ were carried out in Microsoft EXCEL 2000. The curve fittings were calculated using the least-squares method and the solver routine provided by EXCEL. The errors given indicate the accuracy of the method.

\section{${ }^{57} \mathrm{Fe}-\mathrm{ENDOR}$ Spectroscopy}

ENDOR spectra were recorded at X-band frequencies with a commercial Bruker ELEXSYS E580 pulsed spectrometer. All experiments were performed at a temperature of $5 \mathrm{~K}$, controlled with an Oxford helium-flow cryostat. ${ }^{57} \mathrm{Fe}$ Davies-ENDOR spectra were acquired with the standard $\pi_{\text {prep }}-\mathrm{RF}-\pi_{\text {det }} / 2-\tau-\pi_{\text {det }}$ sequence using selective microwave pulses at detection $\left(\pi_{\mathrm{det}}=200 \mathrm{~ns}\right)$ and a hard preparation pulse $\left(\pi_{\mathrm{prep}}=50 \mathrm{~ns}\right)$ to suppress the overlapping proton hyperfine coupling (15). RF pulse lengths were set to $8 \mu$ s to account for the large gamma enhancement factor $\gamma_{\mathrm{enh}} \approx A_{\mathrm{iso}} / 2 \nu_{\mathrm{L}}$. A radiofrequency amplifier (Dressler) allowed a pulse power of about $1 \mathrm{~kW}$ between 5 and $40 \mathrm{MHz}$ with a linearity of 1-2 dB. Acquisition times varied between 3 and $12 \mathrm{~h}$, depending on the spectral position in the EPR line.

\section{XAS Spectroscopy}

HdrABC was purified from M. marburgensis under strict anoxic conditions as described (12). The CoM-SH adduct of HDR was made by oxidizing the enzyme (13 $\mathrm{mg}$ of protein in $1 \mathrm{~mL}$ of $50 \mathrm{mM}$ Tris $/ \mathrm{HCl} \mathrm{pH} \mathrm{7.6)} \mathrm{with} 2 \mathrm{mM}$ duroquinone $\left(E^{\mathrm{o}^{\prime}}=+86 \mathrm{mV}\right)$, followed by addition of $0.5 \mathrm{mM}$ CoM-SH, and incubation at room temperature for $30 \mathrm{~min}$. To remove non-protein-bound substrate, the $1 \mathrm{~mL}$ samples were diluted to $4.5 \mathrm{~mL}$ and then concentrated to $0.1 \mathrm{~mL}$ by ultrafiltration using Amicon Ultra- 4 centrifugal filter units (Millipore) with a $100 \mathrm{kDa}$ cutoff. This washing step was repeated four times. The washed protein was concentrated to $0.1 \mathrm{~mL}$, and ethylene glycol was added to a final concentration of $20 \%$. The sample was placed into a $24 \mathrm{~mm} \times 3 \mathrm{~mm} \times 2 \mathrm{~mm}$ polycarbonate cuvette (with one $24 \mathrm{~mm} \times 3 \mathrm{~mm}$ wall consisting of $0.001 \mathrm{in}$. X-ray-transparent Mylar tape) and immediately frozen in liquid nitrogen. HdrABC in the absence of CoM-SH and $\mathrm{HdrB}$ was 
concentrated and placed in similar cuvettes. The final enzyme concentration was $0.8 \mathrm{mM}$ for $\mathrm{HdrABC}$ and $2 \mathrm{mM}$ for HdrB. All buffers used for sample preparation were pretreated with Chelex 100 cation-exchange resin (Bio-Rad, Muenchen), and plastic materials were rinsed with $10 \mathrm{mM}$ EDTA and distilled water before use.

Zn X-ray absorption spectra were recorded on beam line 9-3 of the Stanford Synchrotron Radiation Laboratory with the SPEAR3 ring operating at $80-100 \mathrm{~mA}(3.0 \mathrm{GeV})$. The vertically focusing mirror was set at $13 \mathrm{keV}$ cutoff for harmonic rejection, and the $1 \mathrm{~mm}$ vertically apertured output of $\mathrm{Si}[220]$-based monochromator created a $1 \mathrm{~mm} \times 4 \mathrm{~mm}$ beam incident on the sample maintained at $10 \mathrm{~K}$ in a LHe flow cryostat. A Canberra 30-element solid-state (intrinsic $\mathrm{Ge}) \mathrm{X}$-ray fluorescence detector was used with a Z-1 $(\mathrm{Cu})$ fluorescent filter and Soller slits to collect fluorescence excitation spectra. Internal energy was calibrated using two $\mathrm{N}_{2}$-filled ionization chambers after the sample, separated by a $\mathrm{Zn}$ foil. Two to five spectra, each of 21 min duration, were collected and averaged for each sample. Data were reduced and analyzed using programs contained within the EXAF-SPAK suite (www.ssrl.slac.stanford.edu/exafspak.html). XAS data were calibrated by defining the first inflection of the $\mathrm{Zn}$ foil edge as $9660.7 \mathrm{eV}$. The $k$ scale was defined using $E_{0}=9670 \mathrm{eV}$. Pre-edge subtraction used a Gaussian model of scatter background, and three-region spline fits were used to extract the EXAFS. Details of Fourier transformation are given in the figure legends.

\section{Other Analytical Procedures}

Non-heme iron was quantified colorimetrically with neocuproin (2,9-dimethyl-1,10phenanthroline) and ferrozine [3-(2-pyridyl)-5,6-bis(4-phenyl sulfonate)-1,2,4-triazine] as described by Fish (24). Prior to analysis adventitious iron was removed by treatment with chelex 100 cation-exchange material (Bio-Rad, Muenchen). Acid-labile sulfur was analyzed as methylene blue (25). Protein concentration was routinely determined by the method of Bradford using serum albumin as the standard (26). HDR activity was determined as described in ref 12 .

\section{RESULTS}

\section{Heterologous Production of M. marburgensis HdrB in E. coli}

M. marburgensis $\mathrm{HdrB}$ was heterologously produced in E. coli. The protein was purified from the $52000 \mathrm{~g}$ supernatant by anion-exchange chromatography and analyzed for the presence of iron-sulfur centers. In the initial $h d r B$ expression studies, a partially soluble but colorless HdrB protein was obtained. The expression conditions were further optimized by coexpressing the E. coli isc genes which encode components of the iron-sulfur cluster biosynthesis machinery. This strategy has also been used for the heterologous production of other iron-sulfur proteins (27). A brown HdrB protein was then obtained. For a high protein yield a rich expression medium and incubation of the cells after induction for $24 \mathrm{~h}$ with agitation and for an additional $24 \mathrm{~h}$ without agitation were found to be important.

The UV/vis spectrum of the protein thus obtained showed maxima at 330 and $417 \mathrm{~nm}$ typical for $[2 \mathrm{Fe}-2 \mathrm{~S}]^{2+}$ clusters (Figure $2 \mathrm{~A}$ ). Upon reduction with sodium dithionite, the absorbance was irreversibly lost, which indicated a cluster breakdown (inset to Figure 2A). In the reduced state no EPR signal characteristic for $[2 \mathrm{Fe}-2 \mathrm{~S}]^{1+}$ clusters was observed. The as-purified protein exhibited an undefined EPR spectrum with a total spin concentration less than $1 \%$ of the protein concentration (Figure $3 \mathrm{~A}$ ). This spectrum did not change significantly upon oxidation by duroquinone or reduction by sodium dithionite. The HdrABC holoenzyme does not contain a [2Fe-2S] cluster, which strongly indicates that the wrong cluster form was inserted into HdrB by the heterologous host. 


\section{Reconstitution and Spectroscopic Characterization of a [4Fe-4S] Cluster}

An in vitro cluster insertion was then attempted. E. coli cell extracts containing HdrB were incubated under anoxic conditions with $\mathrm{FeCl}_{2}, \mathrm{Na}_{2} \mathrm{~S}$, DTT, and cysteine for $12 \mathrm{~h}$ at $25^{\circ} \mathrm{C}$. HdrB purified from these cell extracts showed spectroscopic properties that differed from those of the nonreconstituted protein. UV/vis spectroscopy revealed a broad absorbance spectrum with a maximum around $400 \mathrm{~nm}$ (Figure 2B). Reduction of the reconstituted protein by sodium dithionite resulted in a decrease in absorbance around $400 \mathrm{~nm}$, which could be reversed by addition of duroquinone as oxidant (inset to Figure 2B). Duroquinoneoxidized HdrB exhibited a rhombic EPR spectrum with $g_{z y x}=2.015,1.995$, and 1.950 (Figure 3B). This spectrum is reminiscent of the spectra obtained when the HdrABC holoenzyme was oxidized in the presence of CoM-SH $\left(g_{z y x}=2.013,1.991,1.938\right)$ (Figure $3 \mathrm{D})$ or CoB-SH $\left(g_{z y x}=2.018,1.996\right.$, and 1.954). The rhombic EPR signal of HdrB was observed without broadening at temperatures up to $45 \mathrm{~K}$ and broadened away above $80 \mathrm{~K}$. Formation of this paramagnetic cluster was strictly dependent on the presence of a thiolgroup-containing reducing agent in the reconstitution mixture. The presence of both DTT and cysteine gave the highest cluster yield, although DTT alone was sufficient for formation of the cluster. The spin concentration of the paramagnetic cluster accounted for only $25 \%$ of the protein concentration, which indicated that cluster reconstitution was only partially successful or that only a portion of the $[4 \mathrm{Fe}-4 \mathrm{~S}]$ clusters became paramagnetic after oxidation. The latter is supported by the finding that purified HdrB contained 2.5 mol of iron and $2.3 \mathrm{~mol}$ of acid-labile sulfur per mol which would predict $50 \%$ occupancy of the [4Fe-4S] site. Part of the iron and acid-labile sulfur is also derived from the stable [2Fe-2S] cluster as described below.

In the dithionite-reduced enzyme or redox titrations at potentials below $-250 \mathrm{mV}$ a rhombic signal with $g_{z y X}=2.055,1.977$, and 1.842 was generated (Figure 4D). The spin concentration of this signal varied from batch to batch and accounted to maximal $10 \%$ of the protein concentration. The signal was observed at temperatures up to $50 \mathrm{~K}$ and broadened away at temperatures above $80 \mathrm{~K}$. The $g$ values and temperature behavior indicated that the signal is due to a $[2 \mathrm{Fe}-2 \mathrm{~S}]^{+}$cluster $(28)$. Hence, in addition to the $[4 \mathrm{Fe}-4 \mathrm{~S}]$ cluster the in vitro reconstitution also led to formation of a stable [2Fe-2S] cluster. Since such a cluster has never been observed in the HdrABC holoenzyme (12), it must be considered as an artifact of the reconstitution.

\section{Activity Assays}

The enzymatic activity of the HdrABC holoenzyme has routinely been determined using two enzyme assays: reduction of CoM-S-S-CoB coupled to oxidation of reduced benzylviologen or oxidation of CoM-SH plus CoB-SH to the heterodisulfide coupled to methylene blue reduction (3). Purified and reconstituted HdrB catalyzed neither of these reactions.

\section{Binding of CoM-SH to the Iron-Sulfur Cluster}

Formation of the $g_{z y x}=2.015,1.995$, and 1.950 EPR signal did not depend on the presence of CoM-SH, which would indicate that formation of this signal is an intrinsic property of recombinant HdrB. Binding of either DTT or cysteine, which were both present in the reconstitution mixture, to the cluster can however not be excluded (see Discussion). To test whether the cluster in $\mathrm{HdrB}$ can still bind $\mathrm{CoM}-\mathrm{SH}$, reduced HdrB was incubated with either $\mathrm{CoM}-\mathrm{SH}$ or $\mathrm{CoM}-{ }^{33} \mathrm{SH}$ and subsequently oxidized by duroquinone. A control sample was oxidized in the absence of CoM-SH. The spectrum obtained after oxidation in the presence of CoM-SH was indistinguishable from the spectrum of the control sample. However, the EPR spectrum anisotropically broadened with the sample containing CoM- ${ }^{33} \mathrm{SH}$ (Figure 3C). This anisotropic broadening has been observed previously with the HdrABC 
holoenzyme oxidized in the presence of $\mathrm{CoM}_{-}{ }^{33} \mathrm{SH}$ (14). The broadening results from the hyperfine coupling between the ${ }^{33} \mathrm{~S}$ nucleus, which has a nuclear spin of $3 / 2$, and the paramagnetic iron-sulfur center.

\section{EPR-Monitored Redox Titrations}

The $g_{z y x}=2.015,1.995$, and 1.950 EPR signal was only observed with oxidized HdrB. Reduction by sodium dithionite resulted in a loss of the resonance. In dye-mediated redox titrations performed in the absence of CoM-SH the resonance started to develop at potentials $\geq 200 \mathrm{mV}$ and was stable at potentials up to $0 \mathrm{mV}$. The titration was reversible, and the loss and formation of the resonance was associated with a one-electron redox process with a midpoint potential of $-120 \pm 10 \mathrm{mV}$ (Figure 4A). When the titration was performed in the presence of $1 \mathrm{mM} \mathrm{CoM-SH}$, the midpoint potential was shifted to more negative values $(-175 \pm 10 \mathrm{mV})$ (Figure 4B). The spectrum obtained at $-70 \mathrm{mV}$ is shown in Figure 4C.

\section{${ }^{57} \mathrm{Fe}-\mathrm{ENDOR}$ Spectroscopy}

Figure 5 displays ${ }^{57} \mathrm{Fe}$-pulsed ENDOR spectra of ${ }^{57} \mathrm{Fe}$-enriched $\mathrm{HdrB}$ recorded at the canonical orientations of the $g$ tensor in the EPR line. The ${ }^{57} \mathrm{Fe}$ spectra of CoM-HDR are shown for comparison. Iron resonances of [Fe-S] clusters are usually characterized by doublets centered at one-half of the value of the orientation-dependent hyperfine coupling $A$ and split by twice the ${ }^{57} \mathrm{Fe}$ Larmor frequency ( $\nu_{\mathrm{L}}=0.48 \mathrm{MHz}$ at $3500 \mathrm{G}$ ), according to $v_{ \pm} \approx$ $\left|A / 2 \pm \nu_{\mathrm{L}}\right|$. In the spectra of HdrB and CoM-HDR, several similar resonance regions were easily identified. Closer inspection of the EPR line in the inset of Figure 5 suggested that another paramagnetic species additionally contributes to the ENDOR spectra of HdrB. A reference ENDOR spectrum was recorded outside the EPR line (Figure 5d) and showed two weak resonance regions around 16 and $26 \mathrm{MHz}$. This species could account for the large intensity of the ENDOR spectra at $16 \mathrm{MHz}$ at $B \| g_{1}$ and $B \| g_{2}$, which is not observed in CoM-HDR. The signal could be due to a $[3 \mathrm{Fe}-4 \mathrm{~S}]^{+}$cluster. At unphysiologically high redox potentials $\mathrm{HdrABC}$ also showed a $g=2.02 \mathrm{EPR}$ signal, which is indicative for a $[3 \mathrm{Fe}-4 \mathrm{~S}]^{+}$ cluster (12). We interpreted this cluster as a breakdown product of a [4Fe-4S] cluster with a labile fourth iron, a property often observed for catalytic $[4 \mathrm{Fe}-4 \mathrm{~S}]$ clusters.

Despite this difference, the data illustrated that the most pronounced doublets of the CoMHDR ENDOR spectra are conserved in the spectra of HdrB. In particular, the similarity at $B \| g_{3}$ is striking, where the spectra of $\mathrm{HdrB}$ and CoM-HDR are almost indistinguishable. The result provides evidence that resting $\mathrm{HdrB}$ contains a [4Fe-4S] cluster with an electronic structure very similar to that of the CoM-HDR intermediate. With both CoM-HDR and $\mathrm{HdrB}$ we did not observe a large anisotropy in any ${ }^{57} \mathrm{Fe}$ hyperfine coupling like that reported for the unique five-fold-coordinated iron site in alkylated ferredoxin:thioredoxin reductase (NEM-FTR) (29). This suggests that only four thiol ligands bind to the cluster and that $\mathrm{CoM}-\mathrm{SH}$ or a nonsubstrate thiol replaces one cysteine ligand. Mössbauer experiments, which were not feasible on HDR due to the large number of clusters, are now being carried out on $\mathrm{HdrB}$ to find further support for this model.

\section{Characterization of Cys to Ser Mutants}

HdrB contains a total of 12 cysteine residues. Ten of these residues are found in the two CCG domains (Figure 6). The two remaining cysteine residues at positions 283 and 287 are present only in HdrB from $M$. marburgensis and not conserved in HdrB of other methanogens. To elucidate which residues provide the ligands to the active-site [4Fe-4S] cluster individual cysteine residues or pairs of cysteine residues in CC or CXXC motifs in the two CCG domains were replaced by serine. In addition, the two nonconserved cysteine residues (C283 and $\mathrm{C} 287$ ) were exchanged for serine (Figure 6). In total 11 mutants were generated. After reconstitution of the iron-sulfur cluster the different HdrB variants could be 
purified as soluble proteins. The C193S/C194S and the C231S/C234S double mutants contained low iron-sulfur cluster content as indicated by UV/vis spectroscopy. All other mutants showed a UV/vis spectrum similar to that of wild-type HdrB. Characterization of the purified proteins by EPR spectroscopy revealed that $\mathrm{HdrB}$ with mutations in the Nterminal CCG domain (C9S, C41S/C42S, and C78S/C81S) in the duroquinone-oxidized state showed the wild-type EPR spectrum $\left(g_{z y X}=2.015,1.995\right.$, and 1.950) with similar spin concentrations. In contrast, Cys to Ser mutations in the C-terminal CCG domain (C153S, C193S, C194S, C231S, and C234S and the double mutants C193S/C194S and C231S/ C234S) had a strong effect on the EPR signal of oxidized HdrB. In the oxidized state the C153S, C193S, C194S, and C234S mutants displayed an EPR signal with major $g$ values at 2.005 and 1.964. The signal could be observed at temperatures up to $100 \mathrm{~K}$ without signal broadening and was optimally sharpened at $40 \mathrm{~K}$. Figure $6 \mathrm{C}$ shows the temperature dependence for the $\mathrm{C} 153 \mathrm{~S}$ mutant which is representative for the other mutants. The temperature dependence argues against a conventional $[3 \mathrm{Fe}-4 \mathrm{~S}]^{+}$cluster which, in general, is only detectable at low temperatures (30), although an unusual $[3 \mathrm{Fe}-4 \mathrm{~S}]^{+}$cluster cannot be excluded. Possibly, a cluster with one non-cysteinate ligand, i.e., serinate (31) or solvent $\left(\mathrm{OH}^{-}\right.$or $\left.\mathrm{H}_{2} \mathrm{O}\right)$, is formed in the serine mutants. Alternatively another amino acid residue could step in as ligand. The C193S/C194S and C231S/C234S double mutants showed minor amounts of an undefined signal in the $g=2$ region. The EPR spectrum obtained for the C231S mutant is an overlay of two major signals as shown by measurements at different temperatures. At temperatures above $55 \mathrm{~K}$ only the $g_{z y X}=2.005$ and 1.964 signal could be observed, which is the signal detected in the C153S, C193S, C194S, and C234S mutants. Subtraction of the signal obtained for the C234S mutant from the spectrum of the C231S mutant resulted in a difference spectrum showing a rhombic signal similar to the one obtained for wild-type HdrB but with slightly shifted $g$ values $\left(g_{z y x}=2.021,1.991\right.$, and 1.939) (labeled as DS1 in Figure 6B). The spin concentration was approximately $40 \%$ of that obtained for wild-type HdrB. EPR spectra recorded from HdrB carrying mutations in the two nonconserved cysteine residues $(\mathrm{C} 283 \mathrm{~S} / \mathrm{C} 287 \mathrm{~S})$ showed the $g_{z y x}=2.015,1.995$, and 1.950 signal present in wild-type HdrB. The spectrum contains additional features in the $g=$ 2.01 region. This latter signal remained at temperatures up to $100 \mathrm{~K}$ and was identical to the spectra recorded for the C153S, C193S, C194S, and C234S. Subtraction of the EPR spectrum obtained for the C153S mutant at one-third of its intensity from the C283S/ C287S spectrum resulted in a spectrum (labeled as DS2 in Figure 6B) identical to the wild-type spectrum. Wild-type HdrB and the different mutants contained additional signals in the lowfield region $(g=2.045)$ with varying intensity. The nature of this signal, which has also been observed for some preparations of the HdrABC holoenzyme (12), is not known. Addition of CoM-SH $(1 \mathrm{mM})$ to the different HdrB variants did not alter the EPR spectra of oxidized samples.

Dithionite-reduced HdrB showed a rhombic signal with $g_{z y x}=2.055,1.977$, and 1.842 indicative for a $[2 \mathrm{Fe}-2 \mathrm{~S}]^{+}$cluster (Figure 4D). This signal was also observed in the HdrB mutants carrying mutations in the N-terminal CCG domain and also in the C283S/C287S mutant. HdrB with mutations in the C-terminal CCG domain did not show this signal. In the reduced state these mutants showed undefined EPR spectra of low signal intensity.

\section{XAS Analysis of a Zinc Site in HdrABC and HdrB}

A previous metal analysis of $\mathrm{HdrABC}$ indicated an elevated $\mathrm{Zn}$ content (unpublished data). The SdhE (formerly SdhC) subunit of succinate dehydrogenase from Sulfolobus tokodaii also contains an isolated $\mathrm{Zn}$ site (32). The primary sequence of $\mathrm{SdhE}$ is related to that of HdrB; both sequences contain two CCG domains. Therefore, HdrABC and HdrB were analyzed by X-ray absorption spectroscopy. Figure 7 compares the Zn K-edge XAS data for samples of $\mathrm{HdrB}$ and (duroquinone oxidized) $\mathrm{HdrABC}$ holoenzyme (the latter purified from 
M. marburgensis cells). Edge, EXAFS, and Fourier transforms of HdrB and the as-isolated $\mathrm{HdrABC}$ were essentially identical, which confirmed that the $\mathrm{Zn}$ site in $\mathrm{HdrB}$ is identical to the site in the holoenzyme. Addition of CoM-SH to HdrABC resulted in only minor changes to the local $\mathrm{Zn}$ site structure. The position (ca. $2.3 \AA$ ) of the major peak in the phasecorrected Fourier transforms (Figure 7B) suggested a predominantly S-based Zn coordination sphere. Curve-fitting analysis (Table 1) suggested that the best-fit coordination sphere is $\mathrm{ZnS}_{3}(\mathrm{~N} / \mathrm{O})_{1}$.

\section{DISCUSSION}

Subunit B of heterodisulfide reductase contains two similar cysteine-rich sequence motifs both annotated as CCG domains. This work shows that the C-terminal CCG domain contains a novel [4Fe-4S] cluster binding motif. To accomplish this, HdrB was heterologously produced in E. coli and the iron-sulfur cluster subsequently inserted by in vitro chemical reconstitution.

In the oxidized state the cluster exhibited an EPR spectrum $\left(g_{z y x}=2.015,1.995\right.$, and 1.950) similar to that of CoM-HDR, a catalytic intermediate that is trapped upon oxidation of the $\mathrm{HdrABC}$ holoenzyme when only CoM-SH is present as substrate. The $g$-value anisotropy and relaxation of the active-site cluster in CoM-HDR is distinct from any known oxidized [Fe-S] cluster. Clusters with similar spectroscopic properties have so far only been detected in other CCG-domain-containing proteins (see below). ${ }^{57} \mathrm{Fe}$ ENDOR spectroscopy revealed that the oxidized reconstituted cluster in $\mathrm{HdrB}$ without the substrate is a [4Fe-4S] cluster with an electronic structure very similar to that of CoM-HDR. Although the EPR spectrum of oxidized HdrB was not changed upon addition of CoM-SH, broadening of the signal with $\mathrm{CoM}^{-}{ }^{33} \mathrm{SH}$ as substrate demonstrated CoM-SH binding to the cluster. Furthermore, CoMSH shifted the midpoint potential of the cluster by $55 \mathrm{mV}$ to a more negative potential. The midpoint potential of the cluster in $\mathrm{HdrB}$ in the presence of CoM-SH $(-175 \pm 10 \mathrm{mV})$ is close to that of CoM-HDR in the HdrABC holoenzyme $(-185 \pm 10 \mathrm{mV})$. These data strongly support our model that the cluster in HdrB is the active-site iron-sulfur cluster of $\mathrm{HDR}$. The two canonical [4Fe-4S] clusters of the ferredoxin-like subunit $\mathrm{HdrC}$, the only other conserved subunit of HDR (Figure 1), are suggested to mediate the electron transfer to the active-site cluster. A close interaction of $\mathrm{HdrB}$ and $\mathrm{HdrC}$ may be necessary for formation of the intact active site or binding of $\mathrm{CoB}-\mathrm{SH}$, explaining the lack of catalytic activity of isolated $\mathrm{HdrB}$. To test this hypothesis, the heterologous production of $\mathrm{HdrC}$ in E. coli and coexpression of $\mathrm{HdrC}$ and $\mathrm{HdrB}$ were attempted. In both cases only insoluble $\mathrm{HdrC}$ protein was obtained (data not shown).

In contrast to the $\mathrm{HdrABC}$ holoenzyme, which remained EPR silent when oxidized in the absence of CoM-SH, HdrB showed the CoM-HDR-like EPR signal already in the duroquinone oxidized state, in the absence of CoM-SH. One possible explanation could be that purified HdrB still contained tightly bound DTT or cysteine, which were required for cluster reconstitution. Previous studies with the HdrABC holoenzyme had shown that CoMHDR-like EPR signals are generated when the enzyme is oxidized in the presence of CoBSH or nonsubstrate thiols, such as DTT or cysteine. These paramagnetic species had, however, significantly higher midpoint potentials than CoM-HDR and were therefore considered as artifacts that occur at high redox potentials (12). The observation that the midpoint potential of the cluster in $\mathrm{HdrB}$ was shifted to lower values upon addition of CoM$\mathrm{SH}$ suggests that CoM-SH could replace an artificial ligand. Another explanation for formation of the paramagnetic species in the absence of CoM-SH could be that the cluster in $\mathrm{HdrB}$ has adopted a slightly altered conformation that shifts the midpoint potential to more negative values $(-120 \mathrm{mV})$. Hence, cluster oxidation would be observed already at moderate 
redox potentials, whereas in native HDR this would only be possible at very high redox potentials where cluster breakdown already occurs.

On the basis of the results of the mutational studies we propose that the iron-sulfur cluster in HdrB is coordinated by C153, C193, C194, and C234 of the C-terminal CCG domain. The $\mathrm{C} 231 \mathrm{~S}$ mutant is still able to assemble a cluster with similar electronic and structural properties as the cluster in wild-type $\mathrm{HdrB}$, although the signal intensity is approximately $40 \%$ of that of the wild type. This cysteine residue might have a stabilizing role or function as redox-active cysteine in the catalytic cycle. The data also point to an unusual tandem cysteine coordination of the cluster (C193 and C194). Tandem cysteine coordination of a [4Fe-4S] cluster has only been observed for two other enzymes, based on structural data, the N2 cluster in the Nqo6 subunit of complex I from Thermus thermophilus (33) and APS reductase from Pseudomonas aeruginosa (34). Subunit Nqo6 of complex I and APS reductase exhibit substrate-induced conformational changes, and it has been suggested that tandem cysteine coordination is associated with conformationally dynamic clusters, which could be due to steric clashes that arise from the CysCys ligation (34). Likewise, replacement of one cysteine ligand of the active-site cluster in the HdrABC holoenzyme by $\mathrm{CoM}-\mathrm{S}^{-}$could result in a changed cluster geometry that could result in the changed redox potential of CoM-HDR.

The results give evidence that cysteine residues of only the C-terminal CCG domain are required for formation of the paramagnetic cluster. Both CCG domains contain the same pattern of conserved cysteine residues, but the overall sequence identity between the two domains is only 19\%. A comparison to other CCG domain-containing proteins (e.g., the Dsr and Hme complex described below) shows that cysteine residues in the C-terminal CCG domain are highly conserved whereas cysteine residues in the $\mathrm{N}$-terminal domain are partially replaced by other amino acid residues. This strongly suggests a divergent evolution of the two CCG domains which could have resulted in a different function of the two domains. Our data are also consistent with the previous observation that the CoM-HDR signal in $\mathrm{Hdr} \mathrm{ABC}$ accounted for only 1 spin per molecule. This was repeatedly observed for several independent preparations (12). The same result was obtained for HDR from $M$. barkeri (Hedderich, unpublished results). It cannot be excluded that the N-terminal CCG domain binds a cluster that remains EPR silent. However, the presence of a cysteinecoordinated $\mathrm{Zn}$ site in $\mathrm{HdrB}$ makes this possibility less likely, as discussed below.

$\mathrm{Zn}$ K-edge XAS investigations demonstrated the presence of an isolated $\mathrm{Zn}$ site in the HdrABC holoenzyme with a coordination environment that includes three sulfurs and one nitrogen (or oxygen). Measurements with purified $\mathrm{HdrB}$ showed that the $\mathrm{Zn}$ site is located on this subunit. Since conserved cysteine residues in HdrB are restricted to the two CCG domains and four cysteine residues of the C-terminal CCG domain are engaged in formation of the iron-sulfur cluster we propose that cysteine residues of the N-terminal CCG domain provide the ligands to the $\mathrm{Zn}$ site. This issue will be addressed in the future by $\mathrm{Zn}$ XAS measurements of the Cys to Ser mutants. A Zn site with the same coordination sphere as in $\mathrm{HdrB}$ has also been identified in subunit SdhE of succinate dehydrogenase from Sulfolobus tokodaii (35). SdhE is a homologue of $\mathrm{HdrB}$ that does not contain cysteine residues in addition to those found in the two CCG domains, supporting our suggestion that cysteine residues of a CCG domain provide ligands to the $\mathrm{Zn}$ site. The role of the $\mathrm{Zn}$ site in HDR is not yet known. It could have a structural role or could act as a Lewis acid to activate either $\mathrm{CoM}-\mathrm{SH}$ or a redox-active cysteine for nucleophilic attack as observed for CoM-SHdependent alkyltransferases (36-38).

CCG domains are found in a large number of proteins; however, to date spectroscopic data have only been available for a few of these proteins. Three of these enzymes come from 
sulfate-reducing organisms, the Hme complex from Archaeoglobus fulgidus, the Dsr complex from Desulfovibrio desulfuricans, and the Tmc complex from Desulfovibrio vulgaris (39-41). All three exhibit rhombic EPR signals, similar to that of CoM-HDR, when measured in the oxidized state and in the absence of external thiols. These enzyme complexes contain an HdrD-like subunit with two CCG domains. However, only the cysteine residues of the C-terminal CCG domain are fully conserved. A CoM-HDR-like paramagnetic species has also been identified in succinate-reduced succinate dehydrogenase from Sulfolobus tokodaii (32), which like several other type E succinate dehydrogenases contains an HdrB-like subunit (42). These data combined with the data presented here suggest that coordination of a [4Fe-4S] cluster could be a general property of the C-terminal CCG domain. While the data presented here provide indirect evidence that the cluster in $\mathrm{HdrB}$ is the active-site cluster, the role of this cluster in other CCG domain-containing proteins needs to be addressed in future studies.

\section{Acknowledgments}

We wish to thank Prof. Rolf Thauer for helpful discussions and continuous support. We thank Dr. Takahashi for the gift of pRKISC, Dr. Antonio Pierik for the help with EPR simulations, and Jürgen Koch and Jörg Kahnt for technical assistance. We are also indebted to Prof. Thomas Prisner for giving us access to the pulse ENDOR spectrometer and Dr. M. Hertel for recording some of the CW-EPR spectra.

\section{References}

1. Hedderich R, Klimmek O, Kröger A, Dirmeier R, Keller M, Stetter KO. Anaerobic respiration with elemental sulfur and with disulfides. FEMS Microbiol Rev. 1998; 22:353-381.

2. Thauer RK. Biochemistry of methanogenesis: a tribute to Marjory Stephenson. Microbiology. 1998; 144:2377-2406. [PubMed: 9782487]

3. Hedderich R, Berkessel A, Thauer RK. Purification and properties of heterodisulfide reductase from Methanobacterium thermoautotrophicum (strain Marburg). Eur J Biochem. 1990; 193:255-261. [PubMed: 2121478]

4. Künkel A, Vaupel M, Heim S, Thauer RK, Hedderich R. Heterodisulfide reductase from methanolgrown cells of Methanosarcina barkeri is not a flavoenzyme. Eur J Biochem. 1997; 244:226-234. [PubMed: 9063468]

5. Simianu M, Murakami E, Brewer JM, Ragsdale SW. Purification and properties of the heme- and iron-sulfur-containing heterodisulfide reductase from Methanosarcina thermophila. Biochemistry. 1998; 37:10027-10039. [PubMed: 9665708]

6. Hedderich R, Hamann N, Bennati M. Heterodisulfide reductase from methanogenic archaea: a new catalytic role for an iron-sulfur cluster. Biol Chem. 2005; 386:961-970. [PubMed: 16218868]

7. Argyrou A, Blanchard JS. Flavoprotein disulfide reductases: advances in chemistry and function. Prog Nucleic Acid Res Mol Biol. 2004; 78:89-142. [PubMed: 15210329]

8. Bateman A, Coin L, Durbin R, Finn RD, Hollich V, Griffiths-Jones S, Khanna A, Marshall M, Moxon S, Sonnhammer EL, Studholme DJ, Yeats C, Eddy SR. The Pfam protein families database. Nucleic Acids Res. 2004; 32:D138-141. [PubMed: 14681378]

9. Hedderich R, Koch J, Linder D, Thauer RK. The heterodisulfide reductase from Methanobacterium thermoautotrophicum contains sequence motifs characteristic of pyridine nucleotide-dependent thioredoxin reductases. Eur J Biochem. 1994; 225:253-261. [PubMed: 7925445]

10. Heim S, Künkel A, Thauer RK, Hedderich R. Thiol:fumarate reductase (Tfr) from Methanobacterium thermoautotrophicum. Identification of the catalytic sites for fumarate reduction and thiol oxidation. Eur J Biochem. 1998; 253:292-299. [PubMed: 9578488]

11. Meyerdierks A, Kube M, Lombardot T, Knittel K, Bauer M, Glockner FO, Reinhardt R, Amann R. Insights into the genomes of archaea mediating the anaerobic oxidation of methane. Environ Microbiol. 2005; 7:1937-1951. [PubMed: 16309392] 
12. Madadi-Kahkesh S, Duin EC, Heim S, Albracht SPJ, Johnson MK, Hedderich R. A paramagnetic species with unique EPR characteristics in the active site of heterodisulfide reductase from methanogenic archaea. Eur J Biochem. 2001; 268:2566-2577. [PubMed: 11322875]

13. Duin EC, Madadi-Kahkesh S, Hedderich R, Clay MD, Johnson MK. Heterodisulfide reductase from Methanothermobacter marburgensis contains an active-site [4Fe-4S] cluster that is directly involved in mediating heterodisulfide reduction. FEBS Lett. 2002; 512:263-268. [PubMed: 11852093]

14. Duin EC, Bauer C, Jaun B, Hedderich R. Coenzyme M binds to a [4Fe-4S] cluster in the active site of heterodisulfide reductase as deduced from EPR studies with the $\left[{ }^{33} \mathrm{~S}\right]$ coenzyme M-treated enzyme. FEBS Lett. 2003; 538:81-84. [PubMed: 12633857]

15. Bennati M, Weiden N, Dinse KP, Hedderich R. ${ }^{57} \mathrm{Fe}$ ENDOR spectroscopy on the iron-sulfur cluster involved in substrate reduction of heterodisulfide reductase. J Am Chem Soc. 2004; 126:8378-8379. [PubMed: 15237985]

16. Walters EM, Johnson MK. Ferredoxin:thioredoxin reductase: disulfide reduction catalyzed via novel site-specific [4Fe-4S] cluster chemistry. Photosynth Res. 2004; 79:249-264. [PubMed: 16328791]

17. Walters EM, Garcia-Serres R, Jameson GN, Glauser DA, Bourquin F, Manieri W, Schurmann P, Johnson MK, Huynh BH. Spectroscopic characterization of site-specific [4Fe-4S] cluster chemistry in ferredoxin:thioredoxin reductase: implications for the catalytic mechanism. $\mathrm{J}$ Am Chem Soc. 2005; 127:9612-9624. [PubMed: 15984889]

18. Ellermann J, Hedderich R, Böcher R, Thauer RK. The final step in methane formation. Investigations with highly purified methyl-CoM reductase (component $\mathrm{C}$ ) from Methanobacterium thermoautotrophicum (strain Marburg). Eur J Biochem. 1988; 172:669-677. [PubMed: 3350018]

19. Takahashi Y, Nakamura M. Functional assignment of the ORF2-iscS-iscU-iscA-hscB-hscA-fdxORF3 gene cluster involved in the assembly of Fe-S clusters in Escherichia coli. J Biochem. 1999; 126:917-926. [PubMed: 10544286]

20. Nakamura M, Saeki K, Takahashi Y. Hyperproduction of recombinant ferredoxins in Escherichia

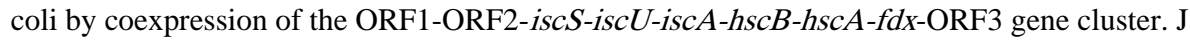
Biochem. 1999; 126:10-18. [PubMed: 10393315]

21. Tong WH, Jameson GN, Huynh BH, Rouault TA. Subcellular compartmentalization of human $\mathrm{Nfu}$, an iron-sulfur cluster scaffold protein, and its ability to assemble a [4Fe-4S] cluster. Proc Natl Acad Sci USA. 2003; 100:9762-9767. [PubMed: 12886008]

22. Sambrook, J.; Russell, DW. Molecular cloning: a laboratory manual. Cold Spring Harbor Laboratory Press; Cold Spring Harbor: 2001.

23. Beinert H, Albracht SPJ. New insights, ideas and unanswered questions concerning iron-sulfur clusters in mitochondria. Biochim Biophys Acta. 1982; 683:245-277. [PubMed: 6297553]

24. Fish, WW. Methods in Enzymology. Riordan, JF.; Vallee, BL., editors. Academic Press Inc; New York: 1988. p. 357-364.

25. Cline JD. Spectrophotometric determination of hydrogen sulfide in natural waters. Limnol Oceanogr. 1969; 14:454-458.

26. Bradford MM. A rapid and sensitive method for the quantitation of microgram quantities of protein utilizing the principle of protein-dye binding. Anal Biochem. 1976; 72:248-254. [PubMed: 942051]

27. Kriek M, Peters L, Takahashi Y, Roach PL. Effect of iron-sulfur cluster assembly proteins on the expression of Escherichia coli lipoic acid synthase. Protein Expr Purif. 2003; 28:241-245. [PubMed: 12699687]

28. Caldeira J, Belle V, Asso M, Guigliarelli B, Moura I, Moura JJ, Bertrand P. Analysis of the electron paramagnetic resonance properties of the $[2 \mathrm{Fe}-2 \mathrm{~S}]^{1+}$ centers in molybdenum enzymes of the xanthine oxidase family: assignment of signals I and II. Biochemistry. 2000; 39:2700-2707. [PubMed: 10704221]

29. Walsby CJ, Hong W, Broderick WE, Cheek J, Ortillo D, Broderick JB, Hoffman BM. Electronnuclear double resonance spectroscopic evidence that $\mathrm{S}$-adenosylmethionine binds in contact with the catalytically active $[4 \mathrm{Fe}-4 \mathrm{~S}]^{+}$cluster of pyruvate formatelyase activating enzyme. J Am Chem Soc. 2002; 124:3143-3151. [PubMed: 11902903] 
30. Beinert H, Thomson AJ. Three-iron clusters in iron-sulfur proteins. Arch Biochem Biophys. 1983; 222:333-361. [PubMed: 6342537]

31. Brereton PS, Duderstadt RE, Staples CR, Johnson MK, Adams MW. Effect of serinate ligation at each of the iron sites of the [4Fe-4S] cluster of Pyrococcus furiosus ferredoxin on the redox, spectroscopic, and biological properties. Biochemistry. 1999; 38:10594-10605. [PubMed: 10441157]

32. Iwasaki T, Wakagi T, Oshima T. Resolution of the aerobic respiratory system of the thermoacidophilic archaeon, Sulfolobus sp. strain 7. III. The archaeal novel respiratory complex II (succinate:caldariellaquinone oxidoreductase complex) inherently lacks heme group. J Biol Chem. 1995; 270:30902-30908. [PubMed: 8537344]

33. Sazanov LA, Hinchliffe P. Structure of the hydrophilic domain of respiratory complex I from Thermus thermophilus. Science. 2006; 311:1430-1436. [PubMed: 16469879]

34. Chartron J, Carroll KS, Shiau C, Gao H, Leary JA, Bertozzi CR, Stout CD. Substrate recognition, protein dynamics, and iron-sulfur cluster in Pseudomonas aeruginosa adenosine $5^{\prime}$-phosphosulfate reductase. J Mol Biol. 2006; 364:152-169. [PubMed: 17010373]

35. Iwasaki T, Kounosu A, Aoshima M, Ohmori D, Imai T, Urushiyama A, Cosper NJ, Scott RA. Novel [2Fe-2S]-type redox center C in SdhC of archaeal respiratory complex II from Sulfolobus tokodaii strain 7. J Biol Chem. 2002; 277:39642-39648. [PubMed: 12167658]

36. Gencic S, LeClerc GM, Gorlatova N, Peariso K, Penner-Hahn JE, Grahame DA. Zinc-thiolate intermediate in catalysis of methyl group transfer in Methanosarcina barkeri. Biochemistry. 2001; 40:13068-13078. [PubMed: 11669645]

37. Kruer M, Haumann M, Meyer-Klaucke W, Thauer RK, Dau H. The role of zinc in the methylation of the coenzyme $\mathrm{M}$ thiol group in methanol:coenzyme M methyl-transferase from Methanosarcina barkeri. Eur J Biochem. 2002; 269:2117-2123. [PubMed: 11985589]

38. Boyd JM, Ensign SA. Evidence for a metal-thiolate intermediate in alkyl group transfer from epoxypropane to coenzyme $\mathrm{M}$ and cooperative metal ion binding in epoxyalkane: CoM transferase. Biochemistry. 2005; 44:13151-13162. [PubMed: 16185083]

39. Mander GJ, Duin EC, Linder D, Stetter KO, Hedderich R. Purification and characterization of a membrane-bound enzyme complex from the sulfate-reducing archaeon Archaeoglobus fulgidus related to heterodisulfide reductase from methanogenic archaea. Eur J Biochem. 2002; 269:18951904. [PubMed: 11952791]

40. Pires RH, Venceslau SS, Morais F, Teixeira M, Xavier AV, Pereira IA. Characterization of the Desulfovibrio desulfuricans ATCC 27774 DsrMKJOP complex-a membrane-bound redox complex involved in the sulfate respiratory pathway. Biochemistry. 2006; 45:249-262. [PubMed: 16388601]

41. Pereira PM, Teixeira M, Xavier AV, Louro RO, Pereira IA. The Tmc complex from Desulfovibrio vulgaris hildenborough is involved in transmembrane electron transfer from periplasmic hydrogen oxidation. Biochemistry. 2006; 45:10359-10367. [PubMed: 16922512]

42. Lemos RS, Fernandes AS, Pereira MM, Gomes CM, Teixeira M. Quinol:fumarate oxidoreductases and succinate:quinone oxidoreductases: phylogenetic relationships, metal centres and membrane attachment. Biochim Biophys Acta. 2002; 1553:158-170. [PubMed: 11803024] 


\begin{tabular}{|c|c|c|c|}
\hline \multirow[b]{2}{*}{$M t \mathrm{Hdr}$} & HdrA & $\mathrm{HdrC}$ & $\mathrm{HdrB}$ \\
\hline & FAD $4[4 \mathrm{Fe}-4 \mathrm{~S}]$ & 2 [4Fe-4S] & $2 \times 5 C$ \\
\hline & HdrE & $\mathrm{Hd}$ & \\
\hline$M b \mathrm{Hdr}$ & 2 heme $b$ & $2[4 \mathrm{Fe}-4 \mathrm{~S}]$ & $2 \times 5 C$ \\
\hline
\end{tabular}

TfrA TfrB

\begin{tabular}{ll|l|l|l|}
\hline MAD & Tfr & FADe-2S] & $2[4 \mathrm{Fe}-4 \mathrm{~S}]$ & $2 \times 5 \mathrm{C}$ \\
\hline
\end{tabular}

Figure 1.

Schematic alignment of heterodisulfide reductase from Methanothermobacter marburgensis $(M t \mathrm{Hdr})$, heterodisulfide reductase from Methanosarcina barkeri (Mb Hdr), and thiol: fumarate reductase from Methanothermobacter marburgensis ( $\mathrm{Mt} \mathrm{Tfr}$ ). Homologous subunits are indicated by the same filling patterns. HdrB, the C-terminal part of HdrD, and the C-terminal part of TfrB contain 10 conserved cysteine residues $(2 \times 5 \mathrm{C})$ in two $\mathrm{CX}_{31-39} \mathrm{CCX}_{35-36} \mathrm{CXXC}$ sequence motifs designated as CCG domains. Subunits HdrE, $\mathrm{HdrA}$, and TfrA have no sequence similarity and different functions in the different enzymes. 

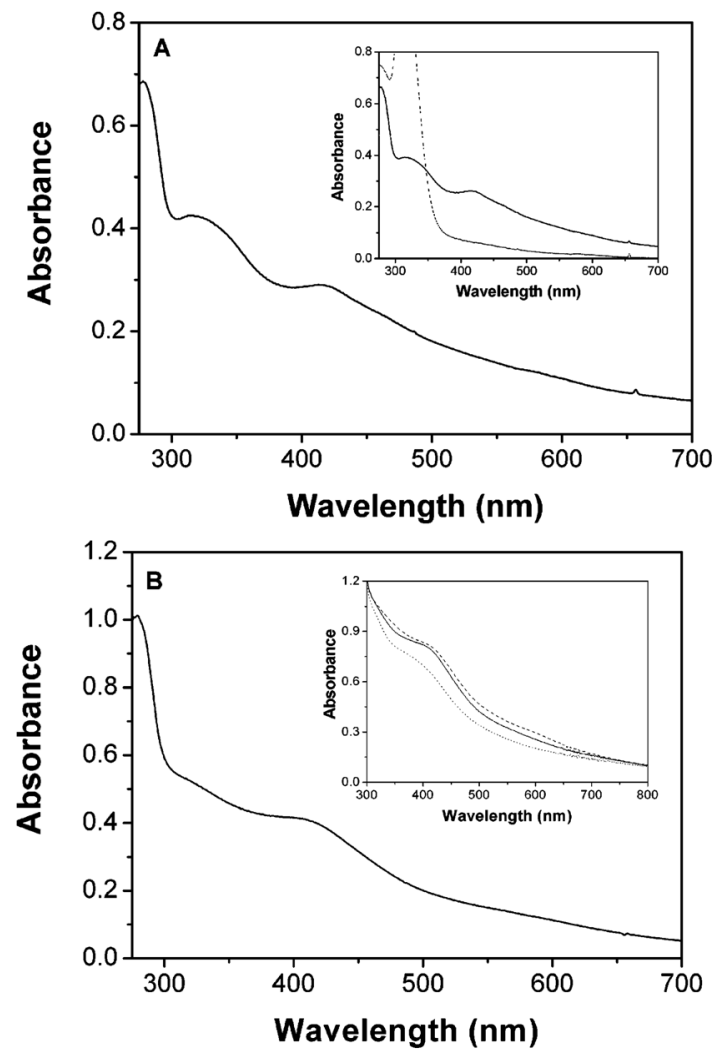

Figure 2.

UV-visible absorption spectra of HdrB produced in E. coli. (A) Spectrum of purified HdrB $(0.7 \mathrm{mg}$ of protein $/ \mathrm{mL})$ obtained from cell extracts without reconstitution. The inset to A shows the spectrum of nonreconstituted HdrB as purified (solid line) and after addition of $0.1 \mathrm{mM}$ sodium dithionite and an incubation of $60 \mathrm{~min}$ (dashed line). (B) Spectrum of HdrB (1 $\mathrm{mg}$ of protein $/ \mathrm{mL}$ ) purified from cell extracts after in vitro reconstitution. The inset to $\mathrm{B}$ shows spectra of reconstituted HdrB (2 mg of protein/mL): in the "as-purified" state (solid line), reduced by $0.1 \mathrm{mM}$ sodium dithionite (dotted line), and the sodium dithionite reduced protein after reoxidation by $0.2 \mathrm{mM}$ duroquinone (dashed line). Protein samples were in 50 $\mathrm{mM}$ Tris/ $\mathrm{HCl} \mathrm{pH}$ 7.6. The spectra were recorded with a Zeiss Specord UV VIS S10 diode array spectrophotometer. 


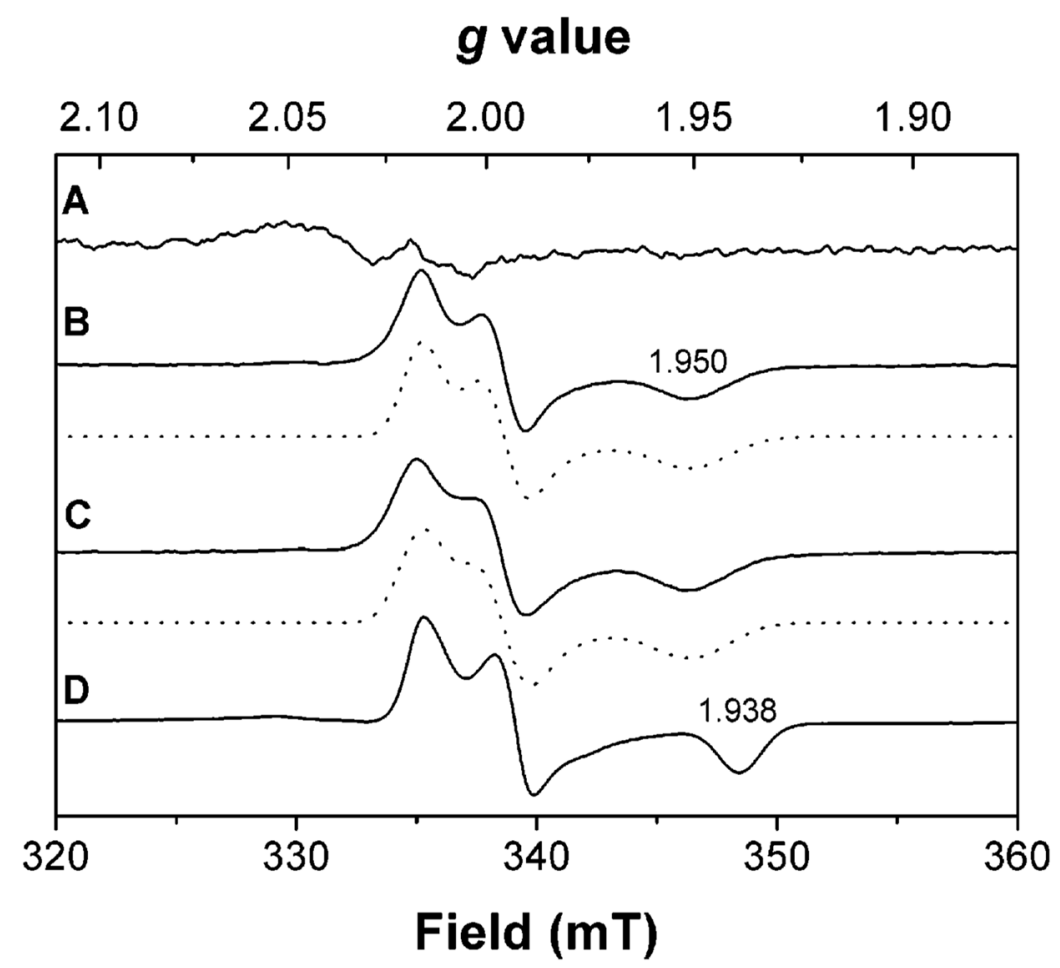

Figure 3.

EPR spectra of HdrB. (A) HdrB $(350 \mu \mathrm{M})$ before reconstitution. (B) HdrB $(100 \mu \mathrm{M})$ after reconstitution. HdrB was oxidized by $2 \mathrm{mM}$ duroquinone. (C) EPR spectrum of HdrB incubated with $\mathrm{CoM}-{ }^{33} \mathrm{SH}$. $\mathrm{HdrB}(100 \mu \mathrm{M})$ was reduced with $5 \mathrm{mM}$ sodium dithionite; excess sodium dithionite was removed by ultrafiltration ( $10 \mathrm{kDa}$ cutoff) and subsequently oxidized by $2 \mathrm{mM}$ duroquinone in the presence of $2 \mathrm{mM} \mathrm{CoM}-{ }^{33} \mathrm{SH}$. Dotted lines represent simulations of spectra B and C. Simulation parameters: $g_{z y x}=2.0147,1.9949,1.9503 ; W_{z y x}$ $=3.00,1.60,1.50 \mathrm{mT} ;\left({ }^{33} \mathrm{~S}, I=3 / 2\right) A_{z y x}=4.00,3.60,0.00 \mathrm{mT}$. (D) Spectrum of CoM-

HDR, shown for comparison. $\operatorname{HdrABC}(40 \mu \mathrm{M})$ was oxidized by $2 \mathrm{mM}$ duroquinone in the presence of $1 \mathrm{mM}$ CoM-SH. EPR conditions: temperature, $20 \mathrm{~K}$; microwave power, 2.007 $\mathrm{mW}$; microwave frequency, $9.458 \mathrm{GHz}$; modulation amplitude, $0.6 \mathrm{mT}$. 
Without CoM-SH

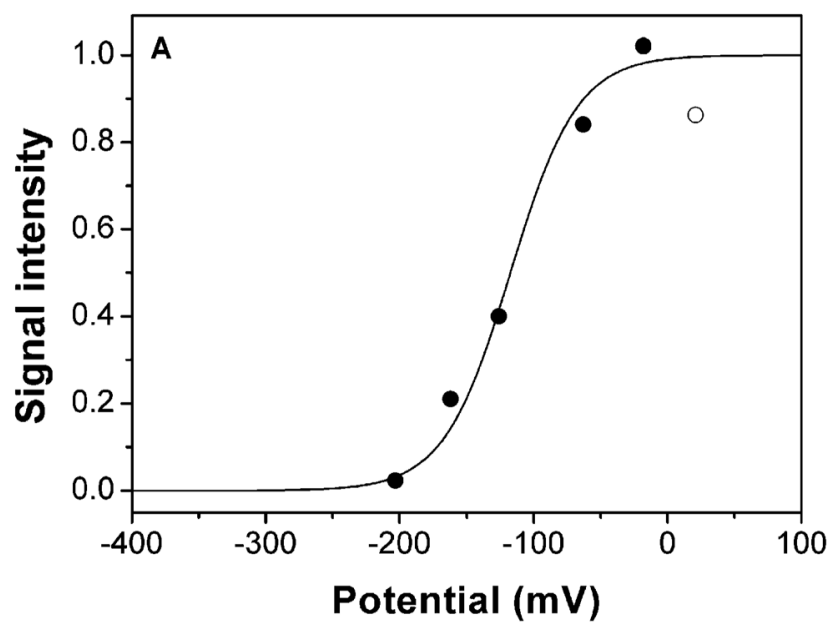

$g$ value

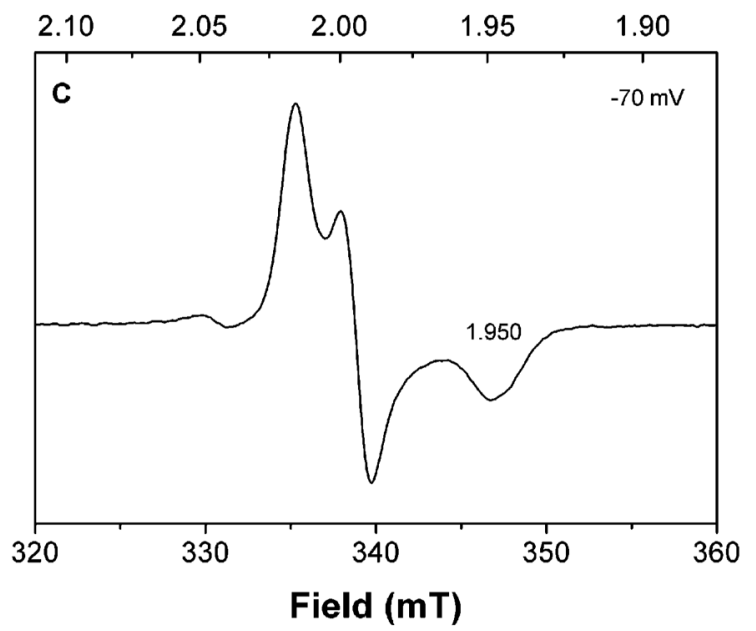

With CoM-SH
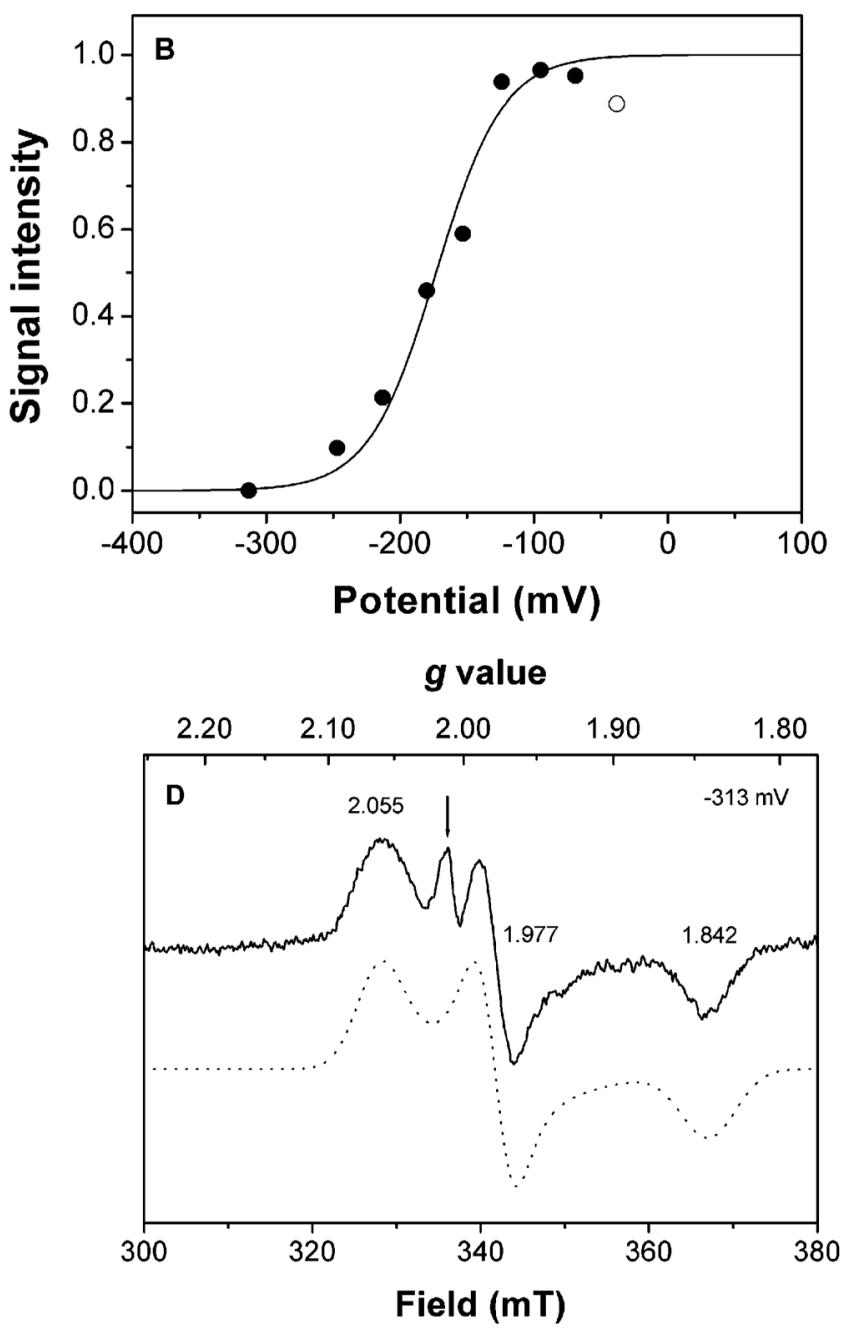

Figure 4.

EPR-monitored redox titration of $\mathrm{HdrB}$ and spectra obtained at different potentials.

Titrations were performed as described in Experimental Procedures. HdrB $(60 \mu \mathrm{M})$ was in $50 \mathrm{mM}$ Tris/ $\mathrm{HCl} \mathrm{pH}$ 7.6. For EPR conditions, see Figure 3A. Titration in the absence of CoM-SH. (B) Titration in the presence of $1 \mathrm{mM} \mathrm{CoM-SH}$. Data points correspond to the amplitude of the trough centered at $g=1.950$ because in the low potential range the radical signals of the dyes overlap in the $g=2.0$ region. The maximal spin concentration was 0.25 per enzyme molecule. The solid lines are $n=1$ Nernst plots with $E_{\mathrm{m}}=-175 \mathrm{mV}$ (in the presence of CoM-SH) or $-120 \mathrm{mV}$ (in the absence of CoM-SH). (C) EPR spectrum obtained at $-70 \mathrm{mV}$. (D) EPR spectrum obtained at $-313 \mathrm{mV}$. The spectra in $\mathrm{C}$ and $\mathrm{D}$ are from the titration in the presence of CoM-SH. The arrow in Figure 3D indicates a radical signal resulting from reduced redox dyes. The dotted line indicates the respective simulation. Simulation parameters for D: $g_{z y x}=2.0550,1.9770,1.8416 ; W_{z y x}=5.70,4.00,6.50 \mathrm{mT}$. At higher potentials $(>0 \mathrm{mV})$ and prolonged incubation partial cluster breakdown was observed. Therefore, the data points indicated by open circles were not used for the Nernst plots. 

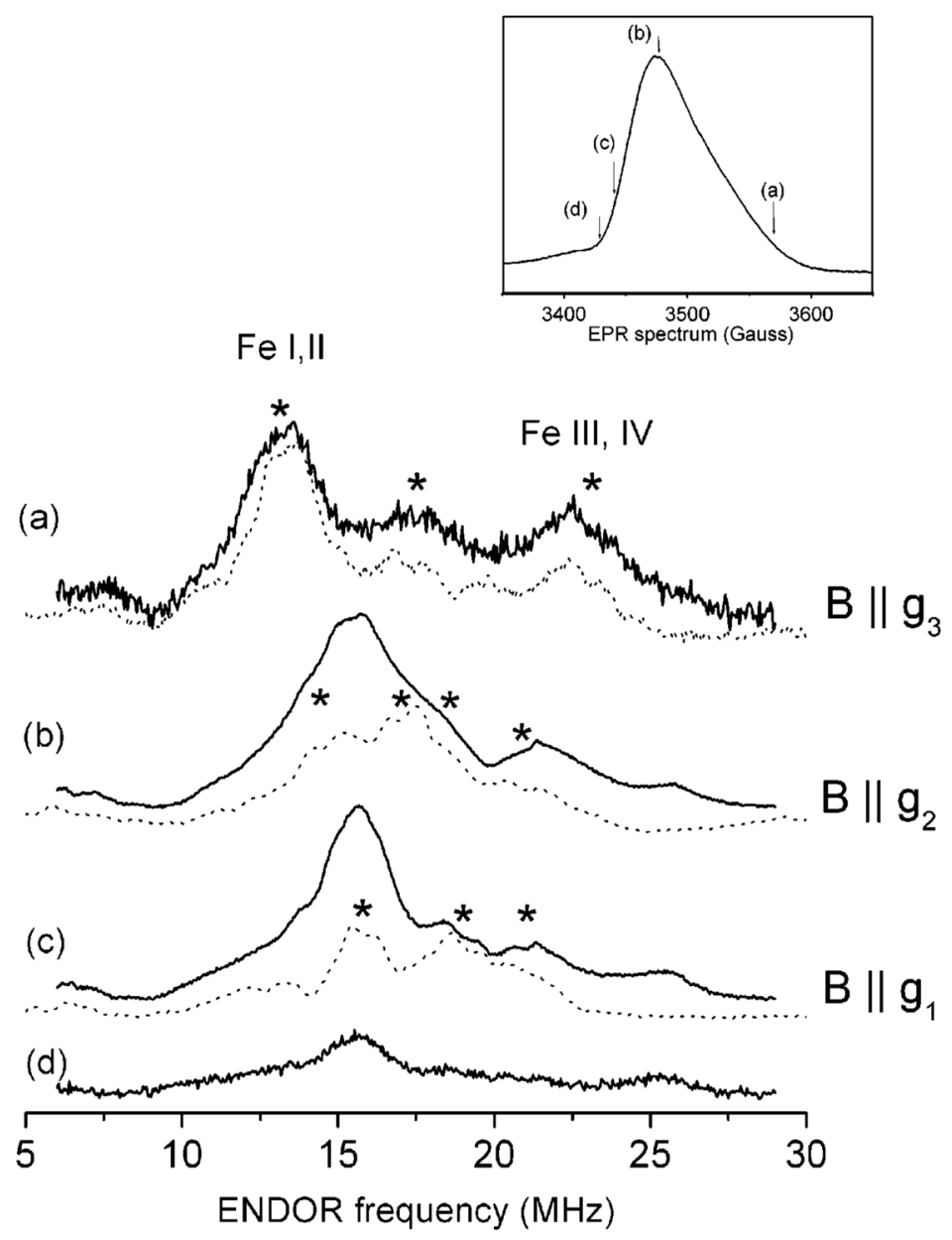

Figure 5.

${ }^{57} \mathrm{Fe}$ Davies ENDOR spectra. Solid lines represent spectra of ${ }^{57} \mathrm{Fe}$-enriched $\mathrm{HdrB}$ recorded at different positions of the EPR line according to (a) $B \| g_{3}$, (b) $B \| g_{2}$, (c) $B \| g_{1}$, and (d) outside the spectrum of HdrB. The inset displays the selected fields in the EPR line. The ${ }^{57} \mathrm{Fe}$ spectra of CoM-HDR are displayed as dotted lines for reference (8). Visible ${ }^{57} \mathrm{Fe}$ doublets that were previously assigned to the resonances of CoM-HDR are indicated (15). $\mathrm{HdrB}(1 \mathrm{mM})$ was in $50 \mathrm{mM}$ Tris/HCl pH 7.6 containing $10 \%$ (v/v) glycerol. 
A
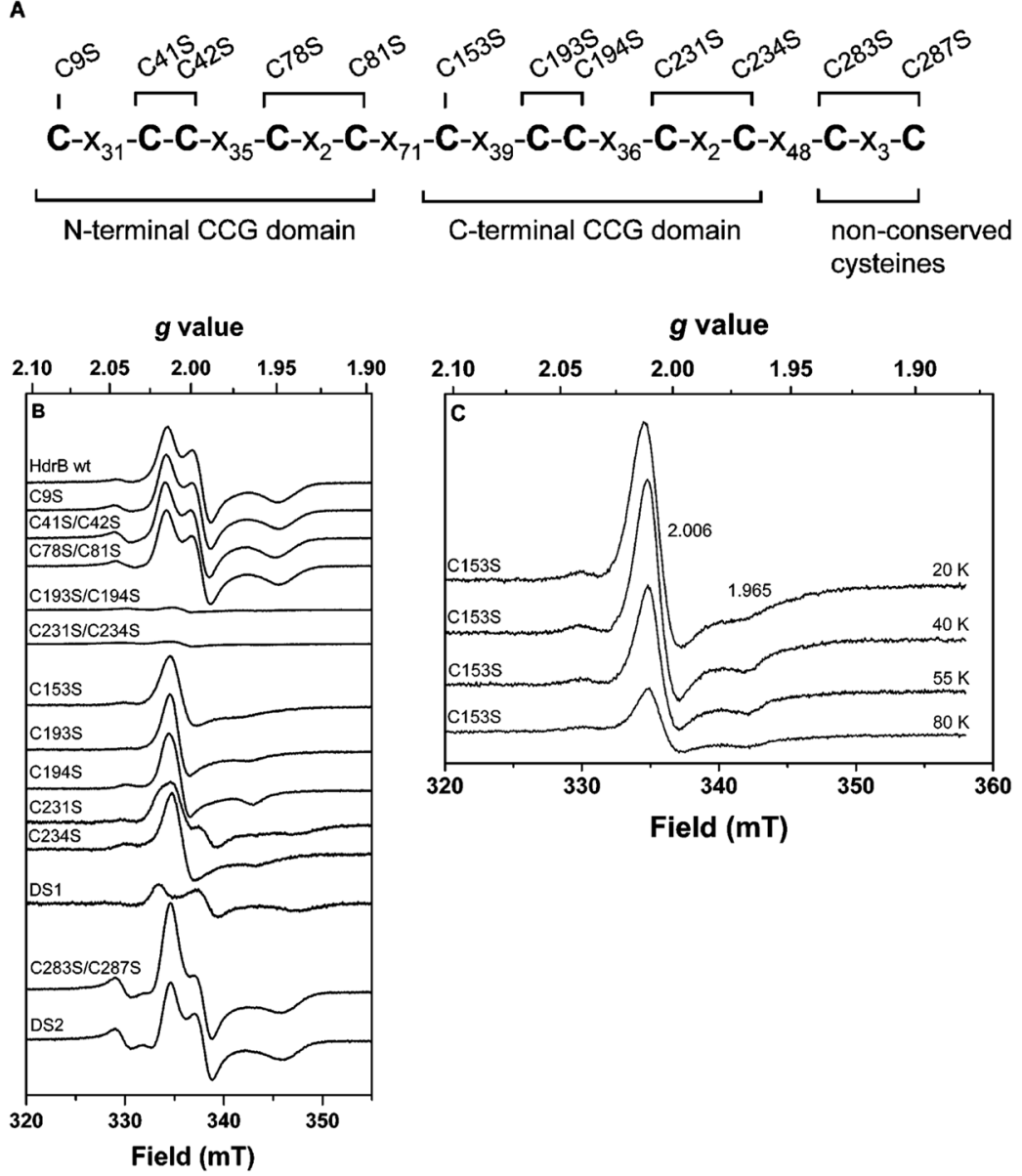

Figure 6.

EPR spectra of oxidized HdrB: wild type and mutants. (A) Representation of the cysteine residues in the two CCG domains and the two nonconserved cysteine residues of HdrB. The Cys to Ser mutants generated are shown above the sequence. (B) EPR spectra. Samples were prepared as described in Figure 3B. For EPR conditions see Figure 3. The spectrum labeled as DS1 is the difference spectrum which was obtained after subtraction of the spectrum of the $\mathrm{C} 234 \mathrm{~S}$ mutant at $60 \%$ of its intensity from the spectrum of the $\mathrm{C} 231 \mathrm{~S}$ mutant. The spectrum labeled as DS2 is the difference spectrum which was obtained after subtraction of the spectrum of the C153S mutant at one-third of its intensity from the spectrum of the C283S/C287S mutant. (C) EPR spectra of the C153S mutant at different temperatures. 

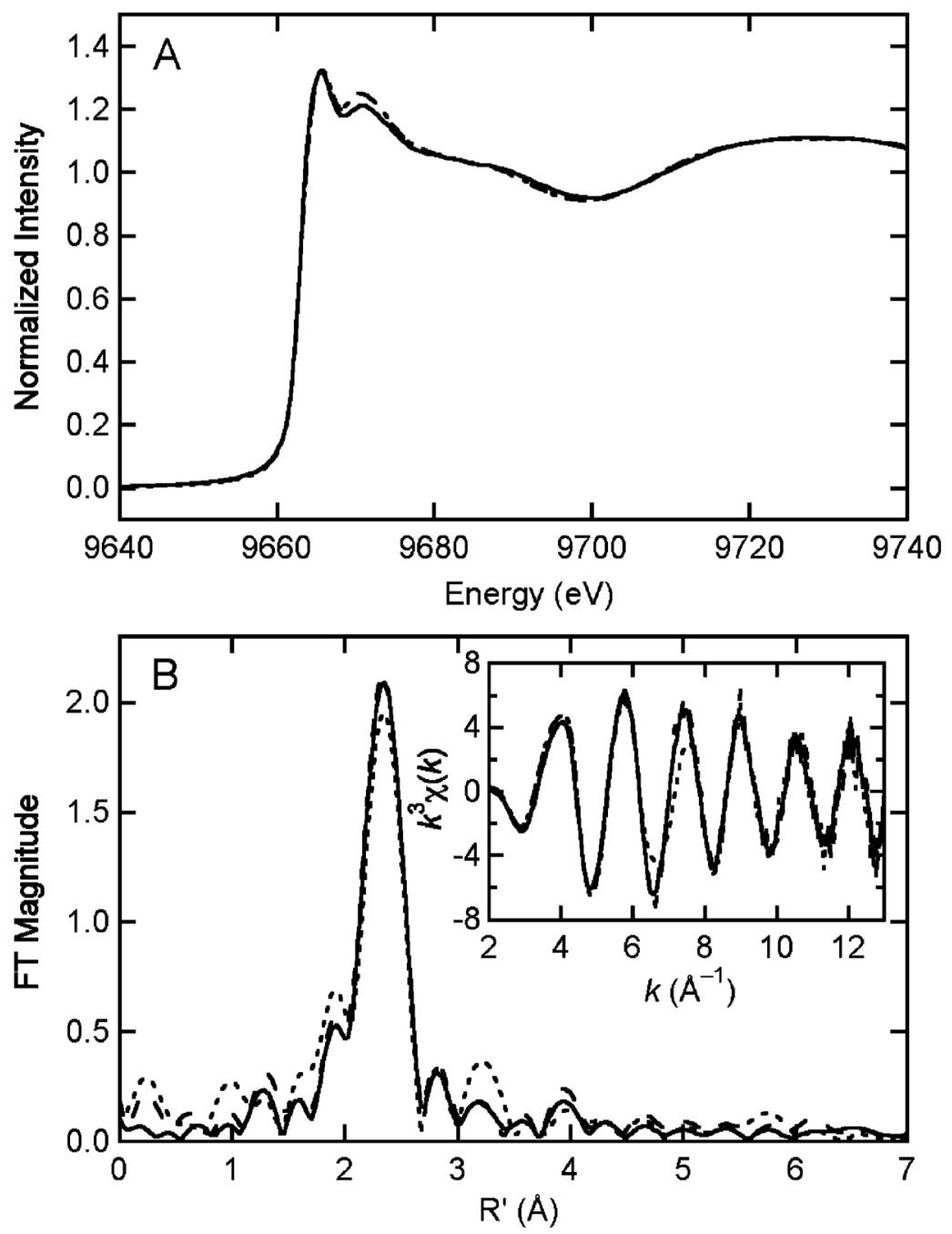

Figure 7.

Zn XAS spectra. (A) Zn K-edge spectra. (B) Fourier transforms $\left(k^{3}\right.$ weighted, $k=2.0-13.0$ $\AA^{-1}$ ) of HdrB (solid line), duroquinone-oxidized HdrABC (long-dashed line), and duroquinone-oxidized HdrABC in the presence of CoM-SH (short-dashed line). (B, inset) $k^{3}$ weighted EXAFS. 


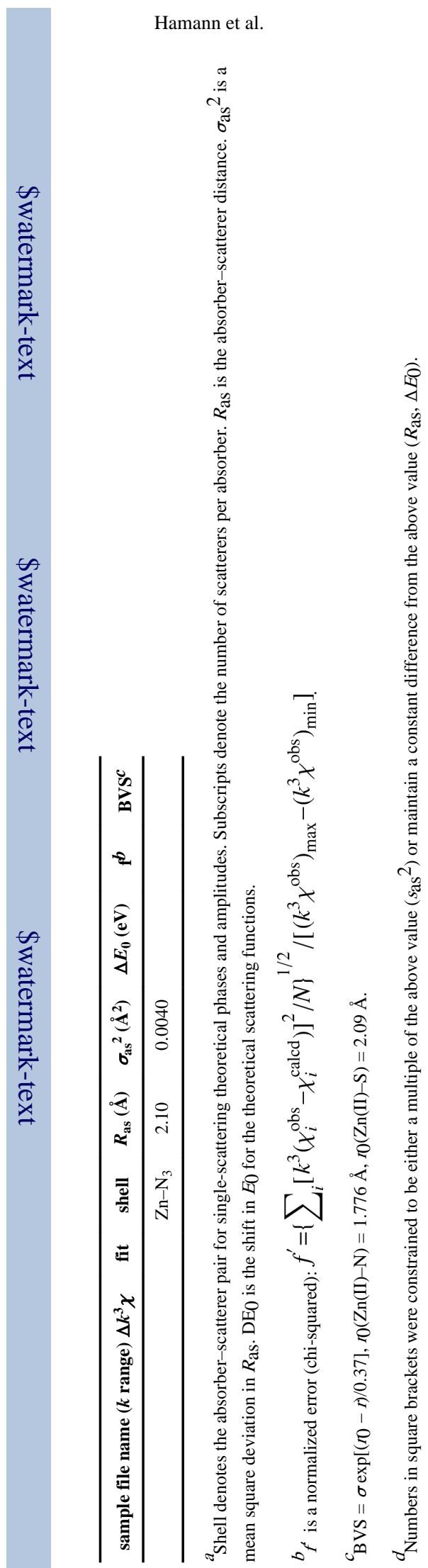

Page 23

Biochemistry. Author manuscript; available in PMC 2013 January 13. 